\title{
The Extracranial-Intracranial Bypass Trial: implications for future investigations
}

\author{
Matthew C. Garrett, B.S., Ricardo J. Komotar, M.D., MaXwell B. Merkow, B.S., \\ Robert M. Starke, B.A., Marc L. Otten, M.D., and E. Sander Connolly, M.D. \\ Department of Neurosurgery, Columbia University, New York, New York
}

\begin{abstract}
$\checkmark$ The 1985 International Extracranial-Intracranial (EC-IC) Bypass Trial failed to show a surgical benefit of EC-IC bypass in patients with varying degrees of angiographic stenosis. This study was limited by the technology available at the time it was conducted. In the 20 years since, there has been considerable progress in imaging techniques that now enable the identification of a subset of stroke patients with hemodynamic ischemia. In the present study, the authors review the relevant literature and propose a reevaluation of the benefits of the EC-IC bypass procedure using these new imaging techniques.

The authors reviewed the admission criteria for the EC-IC Bypass Trial in the light of more recently discovered neurovascular physiology and showed that the imaging criteria used in that trial are not physiologically adequate. A MEDLINE (1985-2007) database search for EC-IC case studies was conducted, and additional studies were identified manually by scrutinizing references from identified manuscripts, major neurosurgical journals and texts, and personal files. (DOI: $10.3171 /$ FOC/2008/24/2/E4)
\end{abstract}

\section{KEY WORDS - carotid angiography - extracranial-intracranial bypass - hemodynamic failure}

$\mathrm{C}$ AROTID artery stenosis has been shown to be highly predictive of stroke. Carotid endarterectomy was designed to treat these patients and has Class 1 evidence to support its efficacy in preventing strokes, but many occlusive lesions are too distal to be accessible., ${ }^{2,436} \mathrm{In}$ 1969 Yaşargil $^{18}$ first described the STA-MCA bypass procedure in which the STA is anastomosed to the MCA. This procedure offered a new hope of treating those with inaccessible carotid and MCA lesions. Proponents of the surgery believed that its anatomical and physiological rationale, in conjunction with the relatively low rates of surgical complications and high patency rates provided sufficient justification for its use. As the procedure was increasingly performed, reports appeared in the literature describing its successful application. Only a few of these case studies had control groups, and none were randomized. Thus, there was a need for a large scale, randomized controlled trial to prove the efficacy of this surgery.

Abbreviations used in this paper: $\mathrm{CBF}=$ cerebral blood flow; EC-IC = extracranial-intracranial; MCA = middle cerebral artery; $\mathrm{PET}=$ positron emission tomography; STA = superficial temporal artery; TIA $=$ transient ischemic attack.

\author{
Results of the EC-IC Bypass Study \\ Methodology and Findings
}

In 1985, the International EC-IC Bypass Trial was published. The entrance criteria included: 1) a history of TIAs or 1 or more minor or completed strokes in the carotid distribution; and 2) the presence of at least 1 of several atherosclerotic angiographic lesions, such as stenosis or occlusion of the trunk or major branches before the bi- or trifurcation of the MCA, stenosis of the internal carotid artery at or above the C-2 vertebral body, or occlusion of the internal carotid artery. The study included 1377 patients who were randomized to surgical or medical therapy. The study hypothesis was that there would be a one third decrease in the stroke rate in those treated with surgery. However, the results rejected this hypothesis with over $99 \%$ power. No patients were lost to follow-up, and none were withdrawn. The average duration of follow-up for surviving patients was 55.8 months, during which period $29 \%$ of patients treated medically experienced 1 or more strokes compared with $31 \%$ in the surgical group (this result did not quite reach statistical significance). ${ }^{3}$

\section{Limitations in Patient Selection}

Critics and the authors of the trial noted 3 major prob- 
TABLE 1

Review of outcome studies with follow-up of patients after EC-IC bypass surgery*

\begin{tabular}{|c|c|c|c|c|}
\hline Authors, Year & $\begin{array}{c}\text { No. of } \\
\text { Patients }\end{array}$ & $\begin{array}{l}\text { Imaging } \\
\text { Modality }\end{array}$ & $\begin{array}{l}\text { Follow-Up } \\
\text { Duration }\end{array}$ & Outcome \\
\hline Ma et al., 2007 & 12 & SPECT w/ ACZ & NA & $\begin{array}{l}\text { Surgery Group: } 4 \mathrm{w} / \text { improved neurological status; } 1 \text { patient w/ a new ischemic } \\
\text { lesion (worsened dysphagia); Medical Group: } 6 \mathrm{w} / \text { stable neurological status }\end{array}$ \\
\hline Hirai et al., 2005 & 40 & SPECT w/ ACZ & 14 days & rCBF \& ACZ reactivity improved \\
\hline Tummala et al., 2003 & 44 & $\mathrm{CT} / \mathrm{Xe}$ & NA & all had preoperative TIAs; $95.4 \%$ had no further ischemic events \\
\hline Neff et al., 2004 & 25 & $\mathrm{CT} / \mathrm{Xe} \mathrm{w} / \mathrm{ACZ}$ & NA & CBF increased after surgery \\
\hline Murata et al., 2003 & 30 & $\mathrm{CT} / \mathrm{Xe}$ & $12 \operatorname{mos}$ & $18 / 30$ patients experienced desaturation on temporal pressure \\
\hline Sasoh et al., 2003 & 5 & PET & $5 \operatorname{mos}$ & 13 had better cognitive improvement; 5 had higher FSIQ score \\
\hline Przbylski et al., 1998 & 42 & $\mathrm{Xe} / \mathrm{CT}$ w/ ACZ & $18-29 \operatorname{mos}$ & 9 patients $(30 \%)$ had stroke prior to surgery; no strokes postsurgery \\
\hline Kuwabara et al., 1998 & 7 & PET w/ ACZ & NA & improved reactivity postoperatively \\
\hline Takagi et al., 1997 & 12 & PET & $36 \operatorname{mos}$ & no strokes \\
\hline Schick et al., 1996 & 40 & CT/SPECT w/ ACZ & $67.2 \operatorname{mos}$ & $23 \%$ improved neurological status, $22 \%$ worsened $\mathrm{w} /$ further ischemic events \\
\hline Ishikawa et al., 1995 & 28 & $\mathrm{SPECT} / \mathrm{Xe}$ w/ ACZ & $27-115 \operatorname{mos}$ & reactivity was increased in all but $1 ; 4 \mathrm{w} /$ lower CBF had strokes $(\mathrm{p}<0.03)$ \\
\hline Schmiedek et al., 1994 & 28 & $\mathrm{SPECT} / \mathrm{Xe}$ w/ ACZ & NA & $82 \%$ had improved CBF \& reactivity \\
\hline Muraishi et al., 1993 & 6 & PET & NA & improved CBF \& OEF \\
\hline Yamashita et al., 1991 & 15 & $\mathrm{CT} / \mathrm{Xe}$ w/ ACZ & NA & $6 / 9$ with low reactivity preoperatively had improved neurological status \\
\hline Holzschuh et al., 1991 & 18 & $\mathrm{CT} / \mathrm{Xe}$ w/ ACZ & NA & surgical group had improved reactivity over 29 control patients \\
\hline Kuroda et al., 1991 & 5 & $\mathrm{SPECT} / \mathrm{Xe}$ w/ ACZ & NA & improved reactivity \\
\hline Pavics et al., 1990 & 32 & 99mTc-SPECT & NA & CBF: 19 unchanged, 7 increased, 6 decreased \\
\hline Kuroda et al., 1990 & 13 & $\mathrm{SPECT} / \mathrm{Xe}$ w/ ACZ & NA & 4 patients had increased reactivity \\
\hline Sunada, 1989 & 9 & $\mathrm{CT} / \mathrm{Xe}$ & NA & no significant change in $\mathrm{CBF}$ \\
\hline Leinsinger et al., 1988 & 31 & SPECT/Xe & NA & increased $\mathrm{CBF}$ \\
\hline Bishop et al., 1987 & 8 & CT/Xe w/ hypercapnia & NA & CBF unchanged, reactivity improved \\
\hline Di Piero et al., 1987 & 14 & SPECT & $12 \operatorname{mos}$ & CBF improved after surgery but no difference at $6 \& 12$ months \\
\hline Vorstrup et al., 1985 & 22 & $\mathrm{CT} / \mathrm{Xe}$ & NA & 20 patients had no increase in $\mathrm{CBF}$ \\
\hline
\end{tabular}

$* \mathrm{ACZ}=$ acetazolamide; FSIQ = Full Scale Intelligence Quotient; NA = not available; OEF = oxygen extraction fraction; SPECT = single photon emission computed tomography.

lems with the entrance criteria. First, the cerebral and retinal ischemic events experienced by the patients in the trial could be of either hemodynamic origin (resulting from poor circulatory perfusion and inadequate collateral vessels) or thromboembolic origin, and it was not possible with angiography to determine which mechanism was responsible. ${ }^{3,6}$ Secondly, angiographic lesions are static representations and do not capture the complex hemodynamics of cerebral circulation. Arterial stenosis or occlusion can cause a reduction in the pressure of distal arterial vessels, but the degree of stenosis or the presence of arterial occlusion does not accurately predict the hemodynamic status of the distal circulation. ${ }^{33}$ Although stenoses of the extracranial carotid artery resulting in reductions in luminal diameter $\geq 50-70 \%$ are known to reduce the distal pressure in some cases, ${ }^{10}$ collateral circulation can maintain normal cerebral perfusion pressure and normal flow in many of these patients. Up to $60 \%$ of patients with complete occlusion of the carotid artery may have no evidence of hemodynamic compromise in the distal circulation. ${ }^{32}$ Third, the study included patients with cerebral ischemia as well those with completed infarctions. Positron emission tomography studies have shown that as CBF falls, oxygen extraction rises to $100 \%$ so that cerebral metabolism becomes totally flow dependent. This is the ideal state for bypass graft placement to increase flow. However, once an acute infarction has occurred, both cerebral oxygen metabolism and arterial oxygen extraction fall to low levels while blood flow paradoxically rises-a state known as "luxury perfusion." Once luxury perfusion becomes established, the use of surgical intervention to increase CBF is inappro- priate because the tissue is not salvageable, and ineffective because the system is no longer low flow.

\section{Implications for Future Investigations}

Better techniques are needed to identify patients with hemodynamic failure. Over the last 20 years, investigators have found 2 different testing methodologies to identify these patients. The first is to evaluate a patient's dilation state with an acetazolamide challenge test. This test involves determining $\mathrm{CBF}$ via xenon-enhanced computed tomography, ${ }^{44}$ transcranial Doppler ultrasonography, ${ }^{9}$ single photon emission computed tomography $\left({ }^{123} \mathrm{I}\right){ }^{16}$ infrared spectroscopy, or magnetic resonance imaging ${ }^{14}$ before and after administration of acetazolamide (similar methods include breath-holding or $\mathrm{CO}_{2}$ inhalation). Acetazolamide acts as a potent vasodilator of the cerebral vasculature and globally increases CBF. Vessels that are already maximally dilated are less reactive and show a smaller increase or no increase in blood flow. In extreme cases, nonselective global vasodilation can act to decrease the blood flow through the strained vasculature, causing a "steal" effect. ${ }^{44}$ The second methodology involves using PET scanning to measure oxygen extraction fraction. When the capacity of vasodilation is insufficient to meet cerebral demand, the brain can increase the amount of oxygen extracted from the blood.

\section{Literature Review}

A MEDLINE (1985-2007) database search was conducted using the following keywords, singly and in combination: EC-IC bypass, hemodynamic failure, and misery 
perfusion; 23 unique EC-IC bypass case series involving 486 patients were found (Table 1). 7,11,17,19,23-31,34,37-39,42-44,47 The authors of 15 of these studies used improved resting CBF and/or improved reactivity as an outcome. Of the 10 studies in which postsurgical resting $\mathrm{CBF}$ was reported, there was an increase in 5 studies ${ }^{17,26,28,30,39}$ and an unchanged or decreased resting CBF in the other 5,7,31,41,45 for a combined rate of 30\% (34/113) of patients showing increased resting CBF. All 8 the studies in which postsurgical reactivity was reported noted a significant increase in reactivity for a combined rate of $80 \%(68 / 86).)^{17,19,20,23-25,39}$

However, the original authors of the 1985 trial raised 3 objections to these case series. First, in the majority of these studies surrogate markers were used (such as blood flow and dilation response) instead of stroke and mortality rates. Improved postoperative stroke rates were reported in only 4 of these case series, and each used the preoperative stroke rate as a control. The second objection was the lack of an appropriate control group. Using pre- and postoperative data is unreliable because the natural course of cerebrovascular reactivity is highly variable, and numerous investigators have reported spontaneous improvement in many patients with impaired cerebrovascular reactivity. ${ }^{16,46,50}$ Third, case studies carry a strong publication bias with many surgeons being motivated to publish neurological improvement over decline.

To address these difficulties, 2 randomized clinical trials were initiated using these new diagnostic modalities. The Japanese EC-IC Bypass Trial ${ }^{21}$ included 206 patients who met the following entrance criteria: 1) symptomatic internal carotid artery/MCA stenosis $\geq 70 \%$ in diameter or an occlusion; 2) independent in daily life (modified Rankin scale $\leq 2$ ); 3) small or no brain infarct, and 4) regional $\mathrm{CBF}$ of the ipsilateral MCA territory $<80 \%$ of the control value and acetazolamide reactivity $<10 \%$. Patients were randomly allocated to EC-IC bypass surgery or medical treatment, and continued with best medical management for 2 years. The authors concluded that the patients in the surgical group showed a statistically significant decrease in stroke rate at 2 years. A second trial (the Carotid Occlusion Surgery Study trial) ${ }^{1}$ is being conducted in the United States using increased oxygen extraction fraction as measured on PET scanning. The specific aim of this second trial is to see if patients identified to have increased oxygen extraction fraction on PET will have better neurocognitive outcomes after EC-IC bypass compared with a medically treated group. Although this trial has flaws (notably using PET, which is scarcely available), if there is a demonstrated benefit it may lead to a resurgence in this procedure.

Given the high cost and great effort involved in these imaging studies, much work has been done to identify clinical features that might aid in identifying these patients. Two classic presentations have been proposed in the literature. The first presentation is TIAs during periods of hypotension either from coughing or standing. ${ }^{8,12,40}$ A more specific type of TIA that has been documented in a few case reports is "orthostatic limb shaking"13 which occurs on standing or neck-bending in 1 or more extremities, and is without electroencephalography correlate. ${ }^{5,48,49,51}$ In the 3 most notable studies, 5 patients with limb-shaking were also shown to have decreased reactivity after inhaling $\mathrm{CO}_{2}{ }^{48}$ and another patient's symptoms resolved after endarterectomy. ${ }^{51}$ In a study in which patients with this presen- tation were followed up over 2 years, the authors found that there was a 5- to 6-fold increased risk of stroke in these patients over those with carotid stenosis only. ${ }^{22}$ Although thought provoking, this is probably a rare presentation (21 cases reported over 30 years), probably with high specificity but low sensitivity.

Another controversial presentation of hemodynamic insufficiency is unilateral blurry vision when looking at bright lights or going from cold to warm environments. ${ }^{15,35}$ It is suspected that the borderline circulation may be unable to sustain the increased retinal metabolic activity associated with bright light. Notably, when 24 patients with this presentation were followed up over 2 years, no patient experienced any cerebral ischemic symptoms. ${ }^{22}$ The authors of this study concluded that this clinical presentation should not be an indication for surgical intervention.

\section{Conclusions}

For the last 20 years, the 1985 EC-IC Bypass Trial constituted the best available evidence with which to judge the efficacy of EC-IC bypass procedures. However, as the technology has advanced, static angiography images are no longer adequate to evaluate low blood flow states. New clinical trials using more sophisticated methodologies for patient selection are now emerging. It is these new trials that will constitute the best available evidence in the years to come.

\section{References}

1. Adams HP Jr, Powers WJ, Grubb RL Jr, Clarke WR, Woolson RF: Preview of a new trial of extracranial-to-intracranial arterial anastomosis: the carotid occlusion surgery study. Neurosurg Clin N Am 12:613-624, 2001

2. Anonymous: Endarterectomy for asymptomatic carotid artery stenosis. Executive Committee for the Asymptomatic Carotid Atherosclerosis Study. JAMA 273:1421-1428, 1995

3. Anonymous: Failure of extracranial-intracranial arterial bypass to reduce the risk of ischemic stroke. Results of an international randomized trial. The EC/IC Bypass Study Group. N Engl J Med 313:1191-1200, 1985

4. Anonymous: North American Symptomatic Carotid Endarterectomy Trial. Methods, patient characteristics, and progress. Stroke 22:711-720, 1991

5. Baquis GD, Pessin MS, Scott RM: Limb shaking - a carotid TIA. Stroke 16:444-448, 1985

6. Barnett HJ: Progress towards stroke prevention: Robert Wartenberg lecture. Neurology 30:1212-1225, 1980

7. Bishop CC, Burnand KG, Brown M, Russell RR, Browse NL: Reduced response of cerebral blood flow to hypercapnia: restoration by extracranial-intracranial bypass. Br J Surg 74:802-804, 1987

8. Caplan LR, Sergay S: Positional cerebral ischaemia. J Neurol Neurosurg Psychiatry 39:385-391, 1976

9. Chimowitz MI, Furlan AJ, Jones SC, Sila CA, Lorig RL, Paranandi L, et al: Transcranial Doppler assessment of cerebral perfusion reserve in patients with carotid occlusive disease and no evidence of cerebral infarction. Neurology 43:353-357, 1993

10. Deweese JA, May AG, Lipchik EO, Rob CG: Anatomic and hemodynamic correlations in carotid artery stenosis. Stroke 1:149-157, 1970

11. Di Piero V, Lenzi GL, Collice M, Triulzi F, Gerundini P, Perani $\mathrm{D}$, et al: Long-term noninvasive single photon emission computed tomography monitoring of perfusional changes after EC-IC 
bypass surgery. J Neurol Neurosurg Psychiatry 50:988-996, 1987

12. Dobkin BH: Orthostatic hypotension as a risk factor for symptomatic occlusive cerebrovascular disease. Neurology 39:30-34, 1989

13. Fisher CM: Concerning recurrent transient cerebral ischemic attacks. Can Med Assoc J 86:1091-1099, 1962

14. Fisher M, Sotak CH, Minematsu K, Li L: New magnetic resonance techniques for evaluating cerebrovascular disease. Ann Neurol 32:115-122, 1992

15. Furlan AJ, Whisnant JP, Kearns TP: Unilateral visual loss in bright light. An unusual symptom of carotid artery occlusive disease. Arch Neurol 36:675-676, 1979

16. Hasegawa Y, Yamaguchi T, Tsuchiya T, Minematsu K, Nishimura T: Sequential change of hemodynamic reserve in patients with major cerebral artery occlusion or severe stenosis. Neuroradiology 34:15-21, 1992

17. Hirai Y, Fujimoto S, Toyoda K, Inoue T, Uwatoko T, Makihara N, et al: Superficial temporal artery duplex ultrasonography for improved cerebral hemodynamics after extracranial-intracranial bypass surgery. Cerebrovasc Dis 20:463-469, 2005

18. Holohan TV: Extracranial-intracranial bypass to reduce the risk of ischemic stroke. Health Technol Assess Rep 6:1-9, 1990

19. Holzschuh M, Brawanski A, Ullrich W, Meixensberger J: Cerebral blood flow and cerebrovascular reserve 5 years after EC-IC bypass. Neurosurg Rev 14:275-278, 1991

20. Ishikawa T, Kamiyama H, Houkin K, Takahashi A, Iwasaki Y, Abe H: Postsurgical observations of mean hemispheric cerebral blood flow with patients receiving high-flow EC-IC bypass using a radial artery graft (preliminary report, one-year observation of 10 hemispheres). Surg Neurol 43:500-509, 1995

21. Jinnouchi J, Toyoda K, Inoue T, Fujimoto S, Gotoh S, Yasumori $\mathrm{K}$, et al: Changes in brain volume 2 years after extracranial-intracranial bypass surgery: a preliminary subanalysis of the Japanese EC-IC trial. Cerebrovasc Dis 22:177-182, 2006

22. Klijn CJ, Kappelle LJ, van Huffelen AC, Visser GH, Algra A, Tulleken CA, et al: Recurrent ischemia in symptomatic carotid occlusion: prognostic value of hemodynamic factors. Neurology 55:1806-1812, 2000

23. Kuroda S, Kamiyama H, Abe H, Takigawa S, Mitsumori K, Nomura M, et al: Drug-induced hypotension SEP test and acetazolamide test using 133Xe SPECT in patients with occlusive carotid disease - selection of candidates for extracranial-intracranial bypass. Neurol Med Chir (Tokyo) 31:7-12, 1991

24. Kuroda S, Takigawa S, Kamiyama H, Abe H, Sakuragi M, Motomiya M, et al: [Diagnosis of hemodynamic compromise in patients with chronic cerebral ischemia; the detection of impaired vasodilatory capacity with $133 \mathrm{Xe}$ SPECT and acetazolamide (Diamox) test.] No Shinkei Geka 18:167-173, 1990 (Jpn)

25. Kuwabara Y, Ichiya Y, Sasaki M, Yoshida T, Fukumura T, Masuda K, et al: PET evaluation of cerebral hemodynamics in occlusive cerebrovascular disease pre- and postsurgery. J Nucl Med 39:760-765, 1998

26. Leinsinger G, Schmiedek P, Kreisig T, Einhaupl K, Bauer W, Moser E: [133Xe-DSPECT: significance of the cerebrovascular reserve capacity for the diagnosis and therapy of chronic cerebral ischemia.] Nuklearmedizin 27:127-134, 1988 (Ger)

27. Ma J, Mehrkens JH, Holtmannspoetter M, Linke R, SchmidElsaesser R, Steiger HJ, et al: Perfusion MRI before and after acetazolamide administration for assessment of cerebrovascular reserve capacity in patients with symptomatic internal carotid artery (ICA) occlusion: comparison with 99mTc-ECD SPECT. Neuroradiology 49:317-326, 2007

28. Muraishi K, Kameyama M, Sato K, Sirane R, Ogawa A, Yoshimoto T, et al: Cerebral circulatory and metabolic changes following EC/IC bypass surgery in cerebral occlusive diseases. Neurol Res 15:97-103, 1993

29. Murata Y, Katayama Y, Sakatani K, Fukaya C, Kano T: Evaluation of extracranial-intracranial arterial bypass function by using near-infrared spectroscopy. J Neurosurg 99:304-310, 2003

30. Neff KW, Horn P, Dinter D, Vajkoczy P, Schmiedek P, Düber C: Extracranial-intracranial arterial bypass surgery improves total brain blood supply in selected symptomatic patients with unilateral internal carotid artery occlusion and insufficient collateralization. Neuroradiology 46:730-737, 2004

31. Pavics L, Doczi T, Blaho G, Bodosi M, Csernay L: [Effect of extra- and intra-cranial vascular anastomosis on regional blood flow, studied by SPECT using 99m-Tc HMPAO.] Orv Hetil 131:2183-2186, 1990 (Hungarian)

32. Powers WJ: Cerebral hemodynamics in ischemic cerebrovascular disease. Ann Neurol 29:231-240, 1991

33. Powers WJ, Press GA, Grubb RL Jr, Gado M, Raichle ME: The effect of hemodynamically significant carotid artery disease on the hemodynamic status of the cerebral circulation. Ann Intern Med 106:27-34, 1987

34. Przybylski GJ, Yonas H, Smith HA: Reduced stroke risk in patients with compromised cerebral blood flow reactivity treated with superficial temporal artery to distal middle cerebral artery bypass surgery. J Stroke Cerebrovasc Dis 7:302-309, 1998

35. Russell RW, Page NG: Critical perfusion of brain and retina. Brain 106:419-434, 1983

36. Sabeti S, Schlager O, Exner M, Mlekusch W, Amighi J, Dick P, et al: Progression of carotid stenosis detected by duplex ultrasonography predicts adverse outcomes in cardiovascular high-risk patients. Stroke 38:2887-2894, 2007

37. Sasoh M, Ogasawara K, Kuroda K, Okuguchi T, Terasaki K, Yamadate K, et al: Effects of EC-IC bypass surgery on cognitive impairment in patients with hemodynamic cerebral ischemia. Surg Neurol 59:455-463, 2003

38. Schick U, Zimmermann M, Stolke D: Long-term evaluation of EC-IC bypass patency. Acta Neurochir (Wien) 138:938-943, 1996

39. Schmiedek P, Piepgras A, Leinsinger G, Kirsch CM, Einhüpl K: Improvement of cerebrovascular reserve capacity by EC-IC arterial bypass surgery in patients with ICA occlusion and hemodynamic cerebral ischemia. J Neurosurg 81:236-244, 1994

40. Somerville ER: Orthostatic transient ischemic attacks: a symptom of large vessel occlusion. Stroke 15:1066-1067, 1984

41. Sunada I: [Measurement of cerebral blood flow by single photon emission computed tomography in cases of internal carotid artery occlusion.] Neurol Med Chir (Tokyo) 29:496-502, 1989 (Jpn)

42. Takagi Y, Hashimoto N, Iwama T, Hayashida K: Improvement of oxygen metabolic reserve after extracranial-intracranial bypass surgery in patients with severe haemodynamic insufficiency. Acta Neurochir (Wien) 139:52-57, 1997

43. Tummala RP, Chu RM, Nussbaum ES: Extracranial-intracranial bypass for symptomatic occlusive cerebrovascular disease not amenable to carotid endarterectomy. Neurosurg Focus 14(3): $\mathrm{E} 8,2003$

44. Vorstrup S, Brun B, Lassen NA: Evaluation of the cerebral vasodilatory capacity by the acetazolamide test before EC-IC bypass surgery in patients with occlusion of the internal carotid artery. Stroke 17:1291-1298, 1986

45. Vorstrup S, Lassen NA, Henriksen L, Haase J, Lindewald H, Boysen G, et al: CBF before and after extracranial-intracranial bypass surgery in patients with ischemic cerebrovascular disease studied with 133Xe-inhalation tomography. Stroke 16:616-626, 1985

46. Widder B, Kleiser B, Krapf H: Course of cerebrovascular reactivity in patients with carotid artery occlusions. Stroke 25: 1963-1967, 1994

47. Yamashita T, Kashiwagi S, Nakano S, Takasago T, Abiko S, Shiroyama Y, et al: The effect of EC-IC bypass surgery on resting cerebral blood flow and cerebrovascular reserve capacity studied with stable XE-CT and acetazolamide test. Neuroradiology 33: 217-222, 1991

48. Yanagihara T, Klass DW: Rhythmic involuntary movement as a 


\section{Extracranial-Intracranial Bypass Trial limitations}

manifestation of transient ischemic attacks. Trans Am Neurol Assoc 106:46-48, 1981

49. Yanagihara T, Piepgras DG, Klass DW: Repetitive involuntary movement associated with episodic cerebral ischemia. Ann Neurol 18:244-250, 1985

50. Yokota C, Hasegawa Y, Minematsu K, Yamaguchi T: Effect of acetazolamide reactivity on [corrected] long-term outcome in patients with major cerebral artery occlusive diseases. Stroke 29:640-644, 1998

51. Zaidat OO, Werz MA, Landis DM, Selman W: Orthostatic limb shaking from carotid hypoperfusion. Neurology 53:650-651, 1999

Manuscript submitted November 10, 2007.

Accepted December 11, 2007.

Address correspondence to: Ricardo J. Komotar, M.D., Department of Neurosurgery, Columbia University, 710 West 168th Street, Room 431, New York, New York 10032. email: rjk2103 @ columbia.edu. 